\title{
A Multivariate Method for the Classification of Preexisting Near-Death Conditions
}

\author{
Stuart W. Twemlow \\ Topeka Institute for Psychoanalysis \\ Topeka, Kansas \\ Glen O. Gabbard \\ The Menninger Foundation \\ Topeka Institute for Psychoanalysis \\ Topeka, Kansas \\ Lolafayne Coyne \\ Statistical Laboratory \\ The Menninger Foundation \\ Topeka, Kansas
}

\begin{abstract}
This study reports the results of a multivariate analysis of data from 33 subjects who had near-death experiences. The analysis examined the relationship between the phenomenology of the experience and preexisting conditions. Five clusters were derived: Low Stress, Emotional Stress, Intoxicant, Cardiac Arrest, and Anesthetic. The heuristic value of these clusters is discussed. The statistical technique used is also discussed in some detail since it is particularly suitable for category data of this type where small numbers of subjects and large numbers of variables are involved in the analysis.
\end{abstract}

\section{INTRODUCTION}

As the scientific literature on the near-death phenomenon gradually increases, speculation about its etiology and meaning shows a parallel increase. This speculation varies in concreteness from transcendental/ mystical/unitive interpretations (e.g., Grosso, 1981; Moody, 1975) to psychological/psychoanalytic/multicausal hypotheses (e.g., Gabbard and Twemlow, 1981; Greyson, 1981) and to pathologizing interpretations (e.g. Siegel, 1980). Such theories also vary along a continuum reflecting more a reductionistic, single-cause view (e.g., Grosso's 1981 concept of an archetype of death) to the multideterministic psychodynamic hypotheses of Gabbard and Twemlow (1981) and Greyson (1981). 
Much work remains to be done, even in the basic characterization of the experience. For example, although evidence is fairly strong that the NDE has specific phenomenological features (e.g., Ring, 1980; Moody, 1975; Drab, 1981; Gabbard, Twemlow and Jones, 1981), many people have life-threatening experiences without such features. The role of expectation of death as a determinant of the experiential features has not been fully explored, since others have NDE-type experiences when not expecting death at all. In a recent report (Twemlow and Gabbard, in press), we examined conditions existing at the time of the near-death experience and found certain experiential and personality features related to the type of illness, injury, or threat existing at the time of the experience. We found that the preexisting conditions have partial explanatory value for the nature and meaning of the experience. In summary, what we called "pre-death experiences" (accident, illness, drug, anesthetic, and fever) are much more like depersonalization than those remembered "after death" (cardiac arrest), which are much more like out-of-body experiences and less like depersonalization.

The current study has two main purposes: 1) presentation of the results of a cluster analysis of data on preexisting conditions to explore the relationship between the phenomenology of the neardeath experience and preexisting conditions; 2) a description of advantages and disadvantages of a particular multivariate approach to data of this type.

\section{METHOD}

Thirty-three subjects who reported a near-death experience were extracted from a larger data pool of 339 subjects who had answered two questionnaires relating to their out-of-body experiences. The methodology and findings of this larger study are reported in detail elsewhere (Twemlow, Gabbard, and Jones, 1982).

Nineteen variables were entered into the analysis as follows:

At the time of your OBE, were you: (1) running a high fever, (2) told that your heart had actually stopped beating, (3) under any emotional stress, (4) unusually fatigued, (5) under the influence of alcohol, (6) under the influence of any drug, (7) under general anesthetic, (8) giving birth to a child, (9) in an accident, (10) in severe pain, (11) in a state of physical relaxation, (12) meditating, (13) in a state of mental calmness, (14) dreaming, (15) if you were dreaming, did the dream involve flying or falling, (16) were you experiencing sexual orgasm, (17) did your OBE occur spontaneously without any 
effort on your part to leave your body, (18) were you driving a car or motorcycle, and (19) did you want to have an OBE? Each question was scored yes or no with room for elaboration in the appropriate places.

The technique used to classify the subjects was a multivariate cluster analysis for category data developed by Friedman and Rubin (1967). This method deals with the problem of clustering a set of objects into homogeneous groups based on measured characteristics of each object. A splitting function is defined to evaluate the amount of structure present in a particular "partition" of the set of data, and then the method attempts to find a partition for which this function is optimized. (A partition is a set of non-overlapping groups with every object belonging to a group.) This is accomplished by means of a "hill-climbing" algorithm, which searches for the optimum partition by continually trying to find a better partition than the one previously found. This hill-climbing algorithm can be used with any splitting function, and it does not require a numerical measure, only a decision as to which of two partitions is better in some sense.

In this application the splitting function is based on a geometric measure, a fixed measure of similarity defined between each pair of objects, and the structure of the data is determined from such a matrix of similarities. This coefficient of similarity is used instead of a distance function when the data is discrete rather than continuous. A set of data is considered to be "well-structured" if it can be split into groups so that similarity coefficients of objects in the same group are generally higher than similarity coefficients of objects in different groups.

The splitting function we use is the average object stability. As a part of the output from the program, we get the stability of each object, the average between-groups similarities, and the object-group average similarity matrix, as well as the average similarity of a group to itself, which is a measure of the internal cohesion of the group. The values for the stability of each object provide us with a way of ranking the objects according to which is most representative of the group; the higher the individual object stability value, the more representative of the group is the object. Five clusters of subjects were derived, and when the relationship among groups was examined, a real structure emerged.

\section{RESULTS}

1. Low-Stress Cluster. The 16 subjects in this group were characterized by being relaxed and calm, not meditating, not under emotional 
stress, not on drugs or alcohol, and without any of the characteristics associated with high anxiety or arousal states. The subjects, however, had a seemingly random distribution of physical causes for their neardeath experience, such as childbirth, illness, accident, etc. None were pyrexic. What is characteristic is their calm and relaxed responses to the experience, in spite of physical circumstances that would normally be accompanied by considerable distress.

2. Emotional-Stress Cluster. The six subjects in this cluster all described themselves as under emotional stress. None were calm, relaxed, or meditating. They were not under the influence of alcohol or drugs during the experience. Once more, other physical preconditions, childbirth, accident, etc. were seemingly randomly distributed.

3. Intoxicant Cluster. This group of four subjects all experienced severe emotional stress without any reports of meditating, being relaxed, or feeling calm. Narcotic drugs and/or alcohol were used in all cases at the time of the NDE.

4. Cardiac-Arrest Cluster. The four subjects in this group all experienced cardiac arrest. Accompanying the arrest, subjects reported a primarily meditative state of mind, not necessarily described as relaxed or calm and associated with dream-like images, especially flying and falling dreams implying a sense of movement within the experience.

5. Anesthetic Cluster. The three subjects in this cluster all experienced a general anesthetic. They described most striking distortions in levels of arousal. Specifically they were under considerable emotional stress, fatigued, but at the same time, paradoxically felt relaxed and calm. The whole experience was dream-like in quality.

In an attempt to ascertain the explanatory value of these clusters, one-way analysis of variance followed by Newman-Keuls individual mean comparisons were performed for a number of key variables. Key variables chosen were: age at the time of reporting the experience, age at the time of the first out-of-body experience, Absorption score (Tellegan and Atkinson, 1974), Danger-Seeking score (Tellegan and Atkinson, 1974), Psychoticism score (Eysenck and Eysenck, 1968), Hysterical Tendency score (Caine, 1972), and Death Anxiety score (Dickstein, 1972). There were no significant differences among the clusters for age, danger-seeking, psychoticism, hysterical tendencies, death anxiety, or absorption. There were significant differences for age of first out-of-body experience between the "low stress" cluster (mean age, 29.9 years) and the cardiac arrest cluster (mean age, 10 years $)(\mathrm{F}=2.956, \mathrm{df}=-, 32, \mathrm{p}<.05)$.

In our previous publication (Gabbard, Twemlow, and Jones, 1981) we made a comparison between subjects who had had a near-death 
experience and other out-of-body subjects. We determined a group of features that were more commonly represented in the near-death subjects. These were: noises heard during the early stages of the experience, traveling through a tunnel, seeing the physical body from a distance, awareness of other beings in a nonphysical form (and particularly of deceased people close to the experiencer), seeing a brilliant light, a sense of purpose connected to the experience, the experience as "life changing," "spiritual or religious" in nature and of "lasting benefit." In view of the small number of subjects in the current study, statistical tests for these individual variables were not made, but what was striking from a calculation of simple percentages was that the tunnel and brilliant-light experiences were much more common in the anesthetic and cardiac-arrest group, being present in all subjects. The cardiac-arrest group stood out further by virtue of all subjects experiencing a sense of power and energy during the experience.

Examination of educational level and sex distribution revealed no striking differences between clusters. The sample has a high percentage of females (68 percent), and subjects were at least high school graduates. The cardiac arrest group tended to be slightly better educated, with some college experience.

\section{DISCUSSION}

\section{Preexisting Conditions}

The heuristic value of these clusters remains to be more fully determined. These preliminary clusters suggest a continuum of neardeath experiences rather than a single unitary experience. The literature has focused most of its attention on the more dramatic experiences associated with cardiac arrest, and indeed, this group stands out in our analysis. The cardiac-arrest group has, in a sense, come closest to confronting death. The power, energy feelings, and flying and falling dreams associated with the arrest could, from a psychoanalytic point of view, be associated with the release of early infantile grandiose feelings, fitting neatly into that category Kohut (1971) described as the "archaic grandiose self." Cardiac-arrest subjects seem also to have experienced out-of-body phenomena at a significantly earlier age than other groups, suggesting a longer familiarity with alterations in mind/body perception.

Inspections of the phenomenological items and items concerning the meaning to the individual suggests that the intoxicant-cluster subjects have experiences that are quite vivid, even bizarre and with a con- 
fused and magical meaning (Twemlow and Gabbard, in press). They are much more like depersonalization with hallucinatory features ("predeath" experiences). It has been suggested that such experiences represent a state-dependent recall of birth trauma (Grof and Halifax, 1978).

The Multivariate Technique as Applied to this Type of Data

Among possible criticisms of this statistical technique are the following: similarity coefficients do not allow the variables to be weighted as to their importance in matches. If too many variables are included, the similarity coefficients will depend on accidental matches or "noise" rather than on matches of the pertinent variables. Variables should be chosen carefully. They should be logically independent. pertinent to the type of classification desired, and limited in number. If variables are of different types, it is likely that there will be more than one possible cluster solution that achieves good structure. Too much variation in the number of states for the set of variables may result in the many-state variables not playing as important a role in the classification procedure as the few-state variables. It would be best to have an equal number of states for each variable and approximately equal frequencies for each state.

From a practical point of view, however, this method allows an investigator to examine his data even when relatively small numbers of subjects are available and relatively large numbers of variables are included. The technique allows quite well-differentiated, meaningful groupings to be derived from small amounts of discrete data and thus is, we feel, often the technique of choice. Typological methods, which attempt to classify discrete data to provide a statistically stable profile, are of considerable value in classifying phenomena such as the near-death or out-of-body experience.

\section{CONCLUSION}

This study and our previous studies have suggested that the differences between near-death experiencers and other subjects who have altered mind/body perceptions lies more in the way in which subjects perceive, interpret, and assign meaning to these experiences, rather than in the traditional psychopathological variables or issues connected with the idiosyncratic nature of the stress itself. Thus a particular illness or life threat is not necessarily a prediction of a particular response from the subject.

Ring (1982) has suggested that the study of near-death experiences may have wide implications for education of children in dealing with 
the universal fear of death and even wider implications politically. Our work over many years with a variety of altered states of consciousness, has indicated that there are the "haves" and the "have nots" in this area. Some people have much greater facility to alter consciousness and others seem simply unable to proceed with the same facility. These differences often produce competitiveness and disappointment; thus, we would strongly suggest that fundamental studies continue in an attempt to elucidate not only the meaning, impact, and philosophical significance of these experiences, but also the variety of ways in which different individuals can have and remember them.

\section{ACKNOWLEDGEMENTS}

The authors would like to thank Betty Rosen and Beth Thompson. The study was supported by The Monroe Institute of Applied Sciences, Faber, Virginia, and the Research Department of the Menninger Foundation, Topeka, Kansas.

\section{REFERENCES}

Caine, T.M. Personality and illness. In R. Miltler (Ed.), Psychological Assessment of Mental and Physical Handicaps. New York: Methuen \& Company, 1972.

Dickstein, L.S. Death concern: measurements and correlates. Psychological Reports, 1972, 30, 563-571.

Drab, K.J. The tunnel experience: reality or hallucination? Anabiosis, 1981, 1 (2), 126-152.

Eysenck, S.B.G., and Eysenck,H.J. The measurement of psychoticism: a study of factor stability and reliability. British Journal of Social and Clinical Psychology, 1968, 7, 286-294.

Friedman, H.P., and Rubin, J. On some invariant criteria for grouping data. Journal of the American Statistical Association, 1967, $62,1149-1178$.

Gabbard, G.O., Twemlow, S.W., and Jones, F.C. Do "near-death" experiences occur only near death? Joumal of Nervous and Mental Disease, 1981, 169 (6), 374-377.

Gabbard, G.O., and Twemlow, S.W. Explanatory hypotheses for near-death experiences. ReVision, 1981, 4 (2), 68-71.

Greyson, B. Toward a psychological explanation of near-death experiences. Anabiosis, 1981, 1 (2), 88-103.

Grof, S., and Halifax, J. The Human Encounter with Death. New York: E.P. Dutton, 1978. 
Grosso, M. Toward an explanation of near-death phenomena. Journal of the American Society for Psychical Research, 1981, 75, 37-60.

Kohut, H. The Analysis of the Self. New York: International Universities Press, 1971.

Moody, R.A. Life After Life. Atlanta: Mockingbird Books, 1975.

Ring, K. Life at Death. New York: Coward, McCann \& Geoghegan, 1980.

Ring, K. Near-Death Studies: A New Area of Consciousness Research. Storrs, Connecticut: International Association for Near-Death Studies, Inc., 1982.

Siegel, R.K. The psychology of life after death. American Psychologist, 1980, 35, 911-931.

Tellegan, A., and Atkinson, G. Openness to absorbing and self-altering experiences ("absorption"): a trait related to hypnotic susceptibility. Journal of Abnormal Psychology, 1974, 53, 368-377.

Twemlow, S.W., and Gabbard, G.O. The influence of demographicpsychological factors and preexisting conditions on the near-death experience. Omega, in press.

Twemlow, S.W., Gabbard, G.O., and Jones, F.C. The out-of-body experience: a phenomenological typology based on questionnaire responses. American Journal of Psychiatry, 1982, 139(4), 450-455.

Requests for reprints to:

Stuart W. Twemlow, M.D.

2145 S.E. Maryland

Topeka, Kansas 66605 